\title{
CIDADE E LUGAR
}

\section{Sua REPRESENTAÇÃo E APROPRIAÇÃo IDEOLÓGICA ${ }^{1}$}

\author{
ESTER LIMONAD \\ RAINER RANDOLPH
}

1 Uma primeira versão deste trabalho foi apresentado no VI Seminário de História da Cidade e do Urbanismo realizado em Natal - RN, outubro de 2000.
R E S U M O Este ensaio tem por meta contribuir para uma discussão atual das representaçôes da cidade e do urbano em um viés que procura articular conceitos comuns da arquitetura e da geografia a partir do conceito de lugar. A argumentação será apresentada em cinco partes: a partir de uma breve caracterização da (i) relação entre cidade e urbano no momento atual em que os indícios apontam para o surgimento de fenômenos cada vez mais "translocais"; passamos a uma (ii) reflexão sobre a relação local-lugar; (iii) a seguir, tratamos do significado e da representação - e sua importância politico-ideológica na formação do lugar - a partir de contribuiçôes da arquitetura e do urbanismo; o que nos leva a questionar (iv) a geração de identidades (culturais) do lugar; para finalizarmos (v) com a apropriação político-prática no assim chamado planejamento estratégico - dimensão trabalhada pelo planejamento urbano.

P A L A V R A S - C H A V E Cidade; lugar; representação; apropriação; urbanização.

\section{INTRODUÇÃO}

Uma série de autores aponta, hoje, a coexistência curiosa e aparentemente paradoxal de duas tendências concomitantes: assiste-se, em sua opinião, ao avanço da urbanização no mundo inteiro, por um lado, e ao desaparecimento da cidade como forma territorial de organização social, por outro.

Nas palavras de Castells \& Borja (1997) a humanidade estaria fadada a um mundo de urbanização generalizada em razão não apenas da concentração da população em áreas urbanas, mas também porque "las áreas rurales formarán parte del sistema de relaciones económicas, politicas, culturales y de comunicación organizado a partir de los centros urbanos" (p.11). A partir daí estes autores questionam a validade de continuarmos a falar de cidades se tudo que conhecemos se tornou urbano, e argumentam se

no deberíamos cambiar nuestras categorías mentales y nuestras políticas de gestión hacia un enfoque diferencial entre las distintas formas de relación entre espacio y sociedad? Tanto más cuanto que otros dos fenómenos definidores de nuestra época histórica plantean la posible desaparición de las ciudades como forma territorial de organización social: la revolución tecnológica informacional y la globalización de la economia y la comunicación. (1997, p.11.)

Seriam, então, três macroprocessos que convergiriam para o desaparecimento da cidade como forma específica de relação entre território e sociedade: a globalização, a informacionalização e a difusão urbana generalizada (p.12). Imagina-se que este mundo 
sem cidades estaria organizado em torno de grandes aglomerações difusas de funçōes econômicas e assentamentos humanos disseminados ao longo de vias de transporte, com zonas semi-rurais nos interstícios, áreas periurbanas incontroladas e com os serviços repartidos em uma infra-estrutura descontínua.

Nosso ensaio parte dessa perspectiva de um suposto fim da cidade num mundo urbanizado - já debatida por nós em outros momentos (Limonad, 1996 e 1999; Randolph, 1998, 1999 e 2000; Randolph \& Limonad, 1998) - não como afirmação de uma realidade já consolidada cujas características empíricas pudessem ser investigadas desde já. Mas como um dos possíveis futuros que, aqui para nós, desafia antes de tudo nossa própria compreensão da cidade e do urbano, da diferença entre urbanização e constituição de cidades, do lugar e do pertencimento das pessoas, de formas de convivência e integração e da própria representação dos lugares como elemento cultural e ideológico.

O que nos interessa neste contexto em particular são as formas de construção e apropriação (cotidiana) das representaçôes como elementos constituintes dos lugares (sua dimensão cultural), que, como tal, constituem também instrumentos e recursos estratégicos empregados para gerar uma percepção ideologicamente estreita dos problemas urbanos (discurso do planejamento estratégico). Cabe esclarecer, no entanto, que não enveredaremos em uma abordagem crítica do planejamento estratégico; neste sentido podemos nos remeter aos trabalhos de Arantes (1998 e 2002) entre outros. Tampouco nos dedicaremos a uma crítica do planejamento urbano e ao seu confronto com o desenho urbanístico, debate que já movimentou gerações de planejadores e urbanistas como Jacobs (1974) e Goodman (1977), apenas para citar duas importantes contribuiçōes, sem falar nos autores nacionais, como Carlos Nelson Ferreira dos Santos (1988) e Maria Adélia de Souza (1988), entre outros.

Trataremos, sim, de aprofundar a reflexão sobre determinados conceitos e categorias que, de certa forma contraditória às tendências acima apontadas, buscam colocar as cidades como protagonistas e que servem, assim, de base para a argumentação do planejamento estratégico. Não há como escapar de uma investigação de caráter fundamentalmente teórico-metodológico - com poucos, mas acreditamos ilustrativos remetimentos empíricos - em razão da referida natureza do nosso objeto de estudo: lidamos hoje com indícios de um mundo urbano sem cidades que pode ou não se tornar realidade - e cuja realização (ou não) dependerá exatamente de nosso posicionamento, de nosso esforço de reflexão e das açôes políticas que porventura possam resultar disto.

Acreditamos que para enfrentar um desafio deste porte - que apenas podemos iniciar aqui -, isto é, enfrentar o "ponto cego" da passagem da cidade industrial para a sociedade urbana do qual Lefebvre (1969) já falou décadas atrás, precisamos retomar e levar adiante a discussão das representaçôes da cidade e do urbano em um viés que procure articular conceitos comuns da arquitetura e da geografia a partir do conceito de lugar. Cabe ressaltar que trabalharemos a representação da cidade e do urbano não no viés da Geografia Cultural em que temos, no Brasil, os trabalhos de Corrêa e Rosendahl (2001 e 2001a) e nem na linha da teoria da percepção da Arquitetura e da Geografia da Percepção da qual existem inúmeras contribuições, entre as quais se destacam as de Ferrara, Del Rio e Oliveira. Nossa intenção é aproximar estas duas disciplinas em torno desse conceito - através da intermediação da obra de Lefebvre, um autor que não pertencia a um nem ao outro campo - o que promete, a nosso ver, a possibilidade de trabalharmos este conceito a partir de uma perspectiva crítica e avançar na compreensão das transformações que apontamos brevemente acima. 
A argumentação será apresentada em cinco partes: (I) a partir de uma breve caracterização da relação entre cidade e urbano no momento atual em que os indícios apontam para o surgimento de fenômenos cada vez mais translocais; passamos a uma (II) reflexão sobre a relação local-lugar; (III) a seguir, tratamos do significado e da representação - e sua importância político-ideológica na formação do lugar - a partir de contribuições da arquitetura e do urbanismo; o que nos leva a (IV) questionar a geração de identidades (culturais) do lugar; para finalizarmos (V) com a apropriação político-prática no assim chamado planejamento estratégico - dimensão trabalhada pelo planejamento urbano.

\section{A CIDADE COMO FENÔMENO TRANSLOCAL}

A cidade, historicamente, constituía-se por excelência no lugar do urbano, por assim dizer. É a manifestação material da urbanização, do processo de tornar urbano, através da ação dos homens, o que não era urbano (Limonad, 1991, p.113); ela nasce, primeiro, da produção do excedente; como lugar da troca e, mais tarde, no feudalismo, como lugar do trabalho livre (Santos, 1991, p.52-3). A cidade, por si só, pressupõe a existência de uma aglomeração física, de pessoas, equipamentos, ou de fixos e fluxos (p.77-8). A respeito do surgimento das cidades existem inúmeros estudos no século XX, desde a clássica revolução urbana de Childe (1950) até as obras de historiadores, urbanistas e geógrafos como Mumford (1998), Jacobs (1974) e Sauer (1952), além das esparsas contribuições de Marx e Engels, no século XIX, sobre a divisão territorial do trabalho e a separação entre a cidade e o campo, objeto de pormenorizado trabalho de Lefebvre (1972a).

Cidade e urbano (ou urbanização), entretanto, precisam ser diferenciados: se a urbanização se refere a uma articulação espacial - contínua ou não - de populações e atividades, a cidade - sem querermos ficar presos a visōes nostálgicas localistas - implica um sistema específico de relações sociais, de cultura e, sobretudo, de instituições políticoadministrativas de autogoverno; isto é, um ambiente onde os cidadãos mantêm algum controle sobre sua própria vida.

Formulado de outra maneira, podemos concordar com Souza (1993) quando fala de lugares da urbanização, na medida em que ser urbano, hoje, não significa necessariamente viver no espaço físico da cidade (p.65) e que partirmos da hipótese de que a urbanização, hoje, extrapola e estende-se além das fronteiras físicas da aglomeração e ganha uma amplitude maior. Mesmo porque, desde sempre a realidade urbana transcende o âmbito local das cidades e sua compreensão necessitava recorrer a superposições e rearticulações de diferentes escalas.

Esse caráter pluriescalar de atividades e fenômenos relacionados à prestação de serviços que, classicamente - lembremos Christaller -, encontravam-se circunscritos à própria cidade, hoje a extrapolam. Isto pode ser notado a partir de alguns exemplos como o serviço de atendimento telefônico em Londres onde as chamadas telefônicas são encaminhadas a um operador em Newcastle especializado em buscar números telefônicos - neste caso pelo fato de em Newcastle se encontrar a pronúncia mais clara. Ou, ainda, quando um agente de viagem em Londres telefona à Lufthansa ou à United Airlines para comprar uma passagem ou marcar um vôo, sua chamada é direcionada a um escritório nas cercanias de Dublin, na Irlanda. Conforme Pawley (1997a,b), mais de 50 centros de atendimento telefônico na Europa de grandes empresas americanas foram instalados na Irlanda, como os da Corel, Digital, Ericsson, Radisson, Oracle, UPS e outros. 
Encontramos aqui uma das principais características da transcendência local da nova realidade urbana: obviamente, nem Newcastle e nem Dublin fazem parte de Londres. Nem estas três cidades constituem uma rede ou sistema de sub ou superordinação como seria o caso das redes entre cidades (Londres como hierarquicamente superior). Ao contrário: são fragmentos de Londres que agora fazem parte de Newcastle e Dublin (e oferecem um serviço não disponível geograficamente - fisicamente em Londres). O sistema de telefone, que até a metade do século XX identificava claramente posições geográficas, agora não é apenas meio para deslocalizações, mas também indício de dis-localização - da impossibilidade de localização -, ou seja, da superação de padrões locais característicos das cidades industriais.

A amplitude dessa mudança revela-se ao considerarmos que a maioria dos negócios se realiza hoje através de telefonemas, que negligenciam a distância e localização geográficas. Na base dessas ligaçóes estabelece-se uma nova forma (interativa) de fluxo de informações, através de redes de computadores, que é, simultaneamente, ponto de partida e resultado para modificações cada vez mais dramáticas na sociedade e nas cidades. Atinge não apenas o mundo corporativo e dos negócios, mas também o dia-a-dia das pessoas, na medida em que os próprios domicílios são equipados com computadores ligados à Internet (Randolph, 2000).

São exatamente essas mudanças que influenciam, crescentemente, a convivência das pessoas no âmbito do seu cotidiano e das suas atividades diárias e rotineiras, responsáveis pela manutenção e fortalecimento de laços sociais estabelecidos tradicionalmente em vizinhanças, bairros ou no convívio mais amplo na cidade. Aqui não devemos esquecer o caráter simbólico da cidade que oferece, na forma e arranjo do seu meio construído, determinadas orientaçôes cotidianas aos moradores da cidade.

Aí podemos observar como o caráter translocal das cidades vem se afirmando, em certa medida, contra sua aparência física e arquitetônica; o endereço e a localização históricos e arquitetônicos de uma série de prédios deixam de corresponder à sua utilização e função originária - ou, como poderíamos dizer, o local insere-se em uma nova totalidade maior que engendra um novo lugar. Torna-se, assim, expressão da intersecção entre diferentes redes (Randolph, 2000) e ganha um nova dimensão e significado.

\section{A RELAÇÃO LOCAL-LUGAR}

A discussão, no item anterior, a respeito de uma suposta rearticulação do relacionamento, nas sociedades atuais, entre cidade e urbano leva-nos a buscar o aprofundamento da reflexão do conceito de lugar. Concordamos, aqui, com Lefebvre (1970) quando, em sua discussão a respeito da superação da cidade industrial, procura por outros termos que não o da cidade. Porque, diz, "estos términos son preferibles a la palabra ciudad", que parece designar "un objeto definido y definitivo, objeto para la ciencia y objectivo immediato de acción... "; ou como ele formula a seguir em outras palavras, não cabe uma ciência da cidade (sociologia urbana, economia urbana etc.), senão um conhecimento em vias de elaboração do processo global, assim como de seu término (objetivo e sentido). Esse novo objeto - eis nossa pergunta - transcenderia os limites locais das cidades (industriais) - seus sitios? Teria como condição e reflexo as novas redes mundiais de computadores e estaria baseada em novos princípios de convivência social, política e cultural que dão origem a novos lugares? 
Conforme Santos (1994), o lugar é o encontro entre possibilidades latentes e oportunidades preexistentes ou criadas (p.44, grifos do autor). De certa forma, podemos adiantar, provisoriamente, que os homens fazem os lugares ao se relacionarem entre si e com a natureza para garantir sua sobrevivência material. Tais relações são mediadas pelo desenvolvimento da técnica e, mais tarde, da ciência e tecnologia, e têm como resultado a transformação do meio natural. No decorrer da história as ações dos homens, as interações e encontros sociais, econômicos, políticos, culturais, religiosos que se desenrolam nestes locais propiciam o surgimento de pontos de concentração e encontro de condições gerais e particulares, que marcam e caracterizam estes locais como particulares, específicos. Estes locais tornam-se, assim, lugares.

O conceito de lugar tem um papel central na geografia. Sua essência variou na história da geografia segundo os paradigmas metodológicos dominantes. Outrossim, encontrar uma definição geral para esse conceito foi, e ainda é, problemático. Pode-se dizer que categorias e linguagens (formas de representação) são instrumentos através dos quais lugares socialmente construídos tornam-se parte do pensamento das pessoas. Nesta passagem de milênio muitos geógrafos questionaram o desaparecimento dos lugares e a emergência de um mundo de fluxos onde o papel dos lugares é dispersado. No presente, fluxos e movimentos são valorizados acima dos lugares. Santos (1996) chama a atenção para as novas formas de regionalização que privilegiariam as verticalidades (fluxos e pontos selecionados) em detrimento das horizontalidades (lugares e regiōes).

Os lugares poderiam ser considerados a manifestação da apropriação do espaço e da natureza pelo homem e pela sociedade, que é inseparável de um dado contexto históricoterritorial (período histórico, época) (Limonad, 1996, p.59-60). Enfim, poderiam ser entendidos como intersecção e concentração de condições gerais, caracterizados pelos fluxos ininterruptos de práticas e experiências humanas (Pred, 1985, p.337) dentro e fora deles.

Os pontos ou sítios tornam-se lugares ao permitirem que haja um entrelaçamento e aglomeração de atividades permanentes e estáveis que os tornem centrais (Lefebvre, 1991, p.331), estratégicos, para as interaçóes intraterritoriais e para as diferentes lógicas que estruturam o território em tempos históricos delimitados. Na escala intra-urbana, historicamente, os pontos predominantes da co-presença social (Giddens, 1985) seriam os locais de residência e de trabalho. Se em contextos menos modernos esses locais são concentrados, em contextos mais avançados ou em transformação, tendem a se distanciar e a se separar, em escalas que vão do local ao territorial.

Estes sítios, todavia, podem ou não se converter em aglomerações urbanas, e, em última instância, em cidades, e isto irá depender necessariamente dos graus e tipos de interações que estabeleçam entre si e outras áreas do território, em diferentes níveis e escalas. As cidades seriam, neste contexto, mais que um meio físico, lugares socialmente criados dentro de um determinado contexto histórico-espacial mais abrangente (por exemplo, as cidades industriais durante o período de industrialização e consolidação do fordismo).

Para além dos sítios da sua presença (e co-presença), as pessoas possuem vínculos com lugares sejam reais ou imaginados (terra prometida). Este laço entre lugares e pessoas é essencial para a construção da identidade coletiva, mas também define o sentido de lugar.

O que nos interessa aqui é que o local parece estar limitado a relações sociais e econômicas (diferentes em cada época histórica); enquanto o lugar, alcançando uma nova dimensão de convivência, condensa uma possibilidade de política - em sentido amplo não restrita às práticas das instituiçōes e dos políticos, mas incluindo as práticas de diferentes grupos sociais. A passagem do local da família (laços sociais) e aldeia (vizinhança; 
laços econômicos) para o lugar da polis (laços políticos) da Antigüidade seria um dos inúmeros exemplos que poderíamos encontrar na história da humanidade.

Política, obviamente entendida aqui como processo de influenciar as ações e tomadas de decisão na sociedade. Em nosso entender a política do lugar refere-se às práticas nas quais as imagens e o sentido de lugar são produzidos e reproduzidos.

Além disso, devemos considerar o papel do poder. Nesse sentido, apoiamo-nos nas consideraçôes de Kuusisto (1999), que trabalha a questão da política no e do lugar para tratar da questão do poder do lugar em comunidades da Irlanda do Norte. Segundo esta autora e Keith \& Pile (1993, p.38), todas as espacialidades (uma das quais é o lugar) são políticas por serem o meio de expressão de relações assimétricas de poder. Decorre daí que o poder, em particular o hegemônico, geralmente definiria o conteúdo e as fronteiras de açôes e práticas de políticas do lugar; por vezes, porém, o poder contra-hegemônico teria condições de conquistar espaço suficiente e consolidar seu lugar - nestas situações, segundo os referidos autores, conflitos de algum tipo tornam-se inevitáveis.

Entendem, portanto, que a política do lugar não deve ser confundida com a política no lugar - a qual não necessariamente inclui dimensões que teriam efeitos sobre a essência ou significado do lugar - ao contrário da política do lugar entre cujas metas a mínima e básica é a alteração da aparência física e mental do lugar. Em decorrência, a política do lugar é particular e específica dos lugares onde é aplicada, e não seria possível generalizar sua aplicação, de maneira indiscriminada, a outros lugares. Há que se destacar também as múltiplas escalas em que a política do lugar é praticada: local, nacional e internacional.

A política do lugar tampouco se restringe a uma delimitação do local. Assim, quando Kuusisto (1999) fala que a política do lugar tem por base práticas restritivas e negações, como, por exemplo, a definição de espaços limítrofes e a exclusão de certos tipos de pessoas e estereótipos negativos, não se deve compreender as restrições e negações localmente. Apenas durante certos períodos históricos a política do lugar esteve localmente definida (por exemplo, durante a afirmação da hegemonia burguesa por intermédio dos Estados nacionais).

Tais práticas, segundo Kuusisto (1999), muitas vezes convertem-se em práticas territoriais coercitivas - nas quais o lugar e o espaço são estritamente guardados e as fronteiras não são permeáveis. Portanto, o que a política do lugar põe em questão, e daí sua importância, são as possibilidades e potencialidades de apropriação do lugar e questionamento do controle hegemônico sobre ele exercido por agentes contra-hegemônicos.

\section{A REPRESENTAÇÃO DO LUGAR}

Acabamos de introduzir, apenas superficialmente, temas como política e poder, hegemonia e contra-hegemonia e outros, com o intuito de compreender o lugar como um conceito mais abstrato do que o da cidade (e que, neste sentido, poderia guiar-nos na busca por um nova articulação entre sociedade e território num período pós-industrial que prescinde da cidade como mediação dominante). Vimos que lugares não são localidades, nem pontos, sítios ou locais; seu caráter é fundamentalmente simbólico (ideológico); construído através de representaçóes.

Pensar as formas de representação do lugar, hoje, obriga-nos a considerar tanto as condiçōes quanto os efeitos da representação se entendemos que, no caso, o objeto - o lugar - e suas representaçóes são inseparáveis, na medida em que o lugar/a cidade é tanto 
o objeto como o produto de práticas significativas, discursos e imagens que lhe conferem legibilidade (ver a respeito Limonad, 2002).

Mais particularmente em relação à cidade - como lugar - sua legibilidade sempre teve um peso importante nos mecanismos de poder e controle da sociedade. Os esforços de torná-la legível significaram e significam, ainda hoje, mapeá-la, torná-la cognoscível, governável e mesmo passível de controle e disciplina (ver Santos, 1988 - seja em âmbito geral ou de sua sintaxe: ruas, monumentos, paisagens etc. - ver Cullen, 1971) e de suas composiçóes. Mesmo no passado, essa legibilidade pressupunha o conhecimento, por parte do leitor - isto é do habitante -, de significados, sintaxes etc. que não se originavam no próprio local (e tempo, para acrescentar a dimensão temporal) da cidade.

É nossa hipótese, derivada da reflexão dos itens anteriores, que o desaparecimento das cidades está acompanhado por uma crescente dificuldade de leitura do meio urbano local(izado). Novamente, recorreremos a uns exemplos que o arquiteto inglês Martin Pawley aponta como indícios do surgimento de uma cidade fantasma - ilegível, tendencialmente incompreensível.

Pawley (1997a) descreve em um dos seus ensaios o caso de um edifício londrino do século XIX, que mantém sua aparência desde sua construção. Este prédio, em cujos pátios ecoava o barulho dos cascos dos cavalos do Correio Real aí sediado, hoje abriga a sede das matrizes européias da Nomura International, maior banco mercantil do mundo. Esta edificação ocupa uma quadra inteira e foi objeto de uma reurbanização que consu-miu um vultoso montante de libras até sua finalização em 1991. Hoje suas paredes abrigam 46.000 metros quadrados de escritórios eletrônicos com ar condicionado em dez andares. Sua aparência é a de um prédio de correio vitoriano, mas possui um coração eletrônico. Conforme Pawley, essa falta de conexão orgânica entre interior e exterior é típica da arquitetura urbana contemporânea: todas as cidades históricas são compostas por edifícios sobressalentes.

A legibilidade do espaço urbano não está apenas colocada em xeque pelo próprio meio localizado (e seus elementos, como prédios, monumentos etc.), mas mesmo por aqueles que seriam seus leitores. As grandes cidades são cada vez mais habitadas por uma população flutuante - os turistas e homens de negócios - cuja atração é, em grande medida, a razão dos esforços de restauração urbana da qual o prédio da Nomura é apenas um exemplo.

Um outro exemplo gritante deste descompasso de usos é o caso do shopping Punta Carretas, situado em uma praia aprazível de Montevidéu, instalado na edificação onde há pouco menos de uma década ainda estava instalado o Presídio Político de Punta Carretas, de onde ecoavam os gritos dos presos políticos torturados. Este caso ilustra a síntese do consumo no lugar e do lugar (ver a este respeito Lefebvre, 1969, p.17). Por um lado converte-se em um dos templos do consumo atual e, por outro, o próprio lugar é consumível como representação do que já foi - sítio imprescindível de qualquer roteiro turístico.

Apenas para indicar a magnitude deste fenômeno, Londres e Nova York, por exemplo, têm uma imensa população flutuante deste tipo; dos 26 milhóes de visitantes de além-mar que vão à Grã-Bretanha cada ano, metade permanece em Londres. Como resultado, a cidade dobra sua população residente por intermédio dos visitantes anuais, e, na alta estação das férias, quase metade da população da área central da cidade consiste de turistas de além-mar (cidadãos ficcionais). Embora possam aparecer como cidadãos comuns na defesa da velha (histórica) substancia urbana, os turistas possuem interesses próprios, relacionamentos, envolvimentos etc. e geram, portanto, articulações dentro da 
cidade totalmente particulares, transitórias, sem envolvimento duradouro no lugar propriamente dito. O fluxo dos turistas pelos quatro cantos do mundo constitui um dos elementos importantes da superação da escala local em muitas cidades. Sua força de influência (indireta) para a formulação de políticas urbanas pode ser identificada não apenas na Grã-Bretanha, mas em qualquer outro lugar do mundo que passe por um upgrade do ambiente urbano para aumentar sua atratividade ao turismo internacional.

Voltando à política urbana na Grã-Bretanha, o turismo é responsável pela adoção de medidas governamentais para expulsar mendigos das ruas da cidade, em consequiência das pesquisas de opinião que mostram que uma elevada porcentagem de visitantes estrangeiros sente-se perturbada por sua presença; assim como o turismo impulsiona a preservação da substância histórica, da renovação urbana, implantação de determinadas infra-estruturas etc. Todo este esforço tem, é óbvio, seu alvo definido: a edição de 1997 do Official Handbook da Grã-Bretanha explica os tipos de turistas desejáveis e indesejáveis:

Um turista dos EUA que gasta muito dinheiro compensa um ônibus completamente lotado daqueles turistas de baixo perfil (os assim chamados day-trippers) do outro lado do Canal da Mancha que chegam com lanches embalados e um itinerário de atraçoes gratuitas que custam ao país mais dinheiro do que eles trazem para cá.

Em outras palavras, os turistas - portadores de redes - são simultaneamente incorporados em redes (de comercialização etc.) das quais mal se dão conta.

Ambos os fenômenos - restauração e fluxo de turistas - fundem-se em uma cena urbana homogeneizada e desistoricizada, de progressiva perda da representação autêntica de tradições e particularidades sócio-locais. Através destes meios, apoiados na aniquilação intencional da distância através de meios eletrônicos, todos os lugares reais e todas as categorias reconhecíveis de edifícios estão desaparecendo: todas as diferenças autênticas entre períodos históricos da arquitetura estão sendo perdidas; seria interessante aqui ver a contribuição da arquitetura pós-moderna e do pós-modernismo para esta situação. E suas strata - diferentes períodos históricos - estão sendo comprimidas como se fora pela ação tremenda de um terremoto. Assim, para o autor - de um ponto de vista urbanístico, da relação entre forma e conteúdo -, a cidade tende a transformar-se em fantasma, numa entidade fora do tempo transcendendo o (seu) lugar.

Se pensarmos, em uma visão mais estreita, a cidade como obra arquitetônica, podese dizer que ela é simultaneamente objeto e representação(ōes) de si mesma. A cidade ainda compreendida como lugar - constitui-se, assim, em um espaço de representação. Além disso, cada um de seus elementos sintáticos (ruas, monumentos, edifícios etc.) constitui também em representações seletivas contraditórias ou afirmativas do significado geral da representação da cidade. Nesse sentido, como representação, a cidade pode ser entendida como uma síntese dialética de si mesma; como condensação de diferentes forças e manifestações.

Para podermos compreender o papel cultural da representação urbana, devemos considerar o espaço social a partir da reflexão da geografia e teoria crítica, que o concebem como um produto e uma relação social (Lefebvre, 1991). Isto tem por corolário a desmistificação da concepção do espaço como natural e transparente, ou mesmo de um continente a ser preenchido com obras arquitetônicas e significações sociais.

Os arranjos espaciais da vida citadina ou composiçôes urbanas podem ser entendidos como sistemas de representação que possibilitam regular, disciplinar e controlar a 
ocupação e uso social do espaço urbano pelos agentes sociais hegemônicos - seja através dos meios de penetração e observação possibilitados pelos elementos físicos componentes da cidade, seja através de identificações e não identificação dos indivíduos com o(s) lugar(es) que contribuem, entre outros fatores, para estabelecer padróes espaciais de centralização e segregação. Isto não significa dizer que o espaço produzido determina as relações sociais - idéia que vicejou tanto na geografia quanto na arquitetura... O que queremos é salientar o papel do fator cultural e da representação e do imaginário social na composição e ordenamento do espaço urbano -, ou seja, há que se considerar que a feição das cidades litorâneas seria muito diferente e haveria uma mudança significativa na distribuição espacial da população e das atividades econômicas se, em meados do século XX, não houvesse se disseminado a moda de se bronzear ao sol e a idéia de que banhos de mar são saudáveis.

Devemos agregar às nossas considerações a necessidade de um aporte crítico às representações dos usos e percepções do espaço urbano e seu papel na construção das esferas privadas e públicas na cidade. Diferentes usos implicam ambientes diferenciados de lazer, trabalho e consumo com sintaxes espaciais próprias e componentes físicos e psicológicos diferentes - que, em um grau ou outro, interferem e contribuem para mediar as relações sociais na cidade. Temos nesse sentido os estudos da gestalt e da percepção do espaço construído - relacionados às formas de possibilitar o encontro, a intimidade e a descoberta (ver Cullen, 1971).

Porém como ficam essas percepções e esses usos quando as relações passam a se dar em um espaço virtual? Num urbano sem cidade?

A modernidade transformou radicalmente os padrões de tempo e espaço (ver a respeito Harvey, 1989) ao comprimir virtualmente o espaço através do tempo - pois não há como diminuir o espaço físico - e, entre suas transformações, propiciou a separação entre os locais de moradia e trabalho, e possibilitou a formação de descomunais aglomerações urbanas - inviáveis e impensáveis até as tranformações introduzidas pelas duas primeiras revoluções industriais. As grandes cidades, assim, converteram-se em metrópoles e em cidades globais - em ícones e sínteses da modernidade.

Como já mencionamos inicialmente e discutimos acima com referência a alguns exemplos, as grandes cidades, hoje chamadas de globais, atuaram como epicentros emblemáticos da modernidade e das novas relações sociais - contribuíram, assim, para a elaboração de distintas representações particulares do moderno em relação à organização do espaço intra-urbano, distribuição da população, consumo etc. e principalmente do visual da modernidade em termos arquitetônicos. A questão é que não podemos admitir estas cidades como produto de uma modernidade universal - admiti-lo implicaria obliterarmos as especificidades de cada uma, tanto em termos espaciais (lugar) quanto temporais (histórico). Portanto, parece-nos que estas cidades devem ser examinadas histórica e dialeticamente em relação às representações de formas e experiências urbanas específicas.

O fim do século XIX e início do século XX assistiram à proliferação de novas tecnologias visuais, formas e textos. Esta proliferação afetou os meios em que a paisagem urbana era representada e as formas com que a paisagem construída era habitada. Há que se considerar, ainda, que estas mesmas formas e representações e sua estruturação influenciam de diferentes modos a consciência temporal e espacial de seus habitantes ao longo do tempo. 


\section{NOVOS LUGARES URBANOS}

A discussão da representação do lugar (e da cidade) leva-nos a questionar como as relações geradoras de espaço e visões na representação urbana estariam relacionadas a uma (pres)suposta identidade urbana, com as correspondências entre indivíduos e comunidades e seus habitats urbanos. Diante das transformações que acompanham a urbanização generalizada, essas correspondências mudam qualitativamente seu caráter.

Através das representações produzidas por diferentes agentes esboçam-se as fronteiras e limites da identificação diferenciada dos habitantes com o sítio e emerge $(\mathrm{m}) \mathrm{o}(\mathrm{s})$ sentido(s) do lugar. Isto não significa dizer que são as representações que produzem o sentido do lugar - dizê-lo seria atribuir um animismo a algo inanimado, ainda que produto de práticas humanas - mas, sim, que através das práticas sociais que possuem representações é possível a construção da identidade coletiva que armazena e historiciza elementos do espaço físico, como marcos de uma memória coletiva, em um processo espaço-temporal de construção identitária.

Ainda dentro de uma perspectiva que sustenta a mencionada correspondência, espaço urbano e subjetividade estariam intrincadamente relacionados; é possível, assim, analisar a formação de respostas conscientes e inconscientes para cenas urbanas em representações literárias e visuais. Formas urbanas e espaços estão imbuídos de conotações afetivas, carregadas de significados emocionais e míticos; em outro lugar aprofundamos essa temática a partir da leitura de Agnes Heller (Randolph, 2002).

Por um lado há uma ampla ressonância no simbolismo da cidade como locus de preocupações nacionais (progresso, segurança e imigração), freqüentemente elaborado em termos amplamente utópicos ou distópicos. Por outro, há formações rochosas, imagens e memórias localizadas associadas aos espaços urbanos e que fornecem significados culturais e suportes históricos para indivíduos e comunidades.

As representaçóes efetivamente, em geral, reproduzem a ordem simbólica da cidade como espaço psíquico. A cidade, como espaço físico, representa não só impulsos conscientes e inconscientes; freqüentemente é representada como um espaço de mistério e de deslocalização.

As mudanças sociais maciças da modernidade tiveram impactos diferenciados em cada lugar, e as cidades modernas emergem como ícones específicos destas mudanças a partir de representaçóes idealizadas da urbanidade tomadas como as verdadeiras essências da vida citadina. As cidades contemporâneas exibem fatores comuns, porém com distintas geografias das diferenças sociais e relações de poder. Seu espaço social, temporalmente e especificamente produzido pelas práticas sociais, é o molde básico de suas identidades urbanas. Assim, a despeito de certas homogeneizaçôes, permanecem as especificidades que estão em sua própria formação e que as constituíram espaço-temporalmente em lugares no território.

Em síntese, tradicionalmente - reportando-nos à tradição da cidade industrial - a cidade foi vista como lugar privilegiado da construção cultural (através de representações das mais diversas formas) da identidade subjetiva e coletiva. Torna-se problemática tanto a construção como o próprio credo na identidade, na medida em que a cidade ameaça desaparecer, tornando-se cada vez mais lugar, conforme debatemos anteriormente. Será que a dissolução da cidade resulta numa diluição do sujeito que perde os parâmetros (representação) para sua identificação? 
Na opinião de Borja \& Castells (1997), a dissolução da cidade e uma possível diluição do sujeito não significam nenhuma fatalidade inexorável. Acreditam ser necessário, diante dessa problemática, "renovar el papel específico de las ciudades en un mundo de urbanización generalizada, proponiendo la construcción de una relación dinámica y creativa entre lo local y lo global" (p.12s). Estes autores tentam mostrar como o âmbito políticoadministrativo em relação a representação e gestão políticas tem a mesma importância estratégica na projeção do local como centro de gestão do global do que os dois outros por eles apontados: o âmbito econômico (elemento chave da produtividade e competitividade econômicas) e o sociocultural, como elemento de integração.

As cidades estão longe de desaparecer - "protagonistas de nuestra época", "atores politicos" (Borja \& Castells, 1997, p.139-83) de sua história que escrevem junto com os cidadãos e governos.

Parece-nos questionável esta afirmação, pois nos tempos atuais de competição e competitividade entre cidades, e luta pelas melhores condiçôes locacionais para atrair dinheiro e pessoas (ver a respeito a discussão de Santos, 1996, e Benko \& Lipietz, 1995). Talvez devêssemos recordar-nos das reflexões de Lojikine sobre as condiçōes gerais da produção e de formas de cooperação urbana que pareciam (também para Marx ainda) indispensáveis para a reprodução do capital. Será que hoje, na network society (Castells, 1999) - onde os circuitos dominantes passam por outras esferas virtuais de acumulação - as cidades perderam essa capacidade?

Parece-nos, em uma primeira apreciação, que as propostas de melhorar as vantagens comparativas de uma cidade continuam presas e partem de uma visão equivocada, ao tratarem as cidades como indivíduos, atores (sociais e/ou políticos) com identidade própria ou ainda como simples bens (mercadorias) ou como entidades autônomas que se enfrentam num mercado pulverizado, oferecendo suas externalidades locais e urbanas como mercadoria para quem queira se valer delas.

Uma série de planos e propostas atualmente em circulação na América Latina parte, a nosso ver, desta visão de um liberalismo urbano - como é o caso, por exemplo, dos Planos Estratégicos que já foram elaborados em diferentes lugares (inclusive no Rio de Janeiro e alguns dos municípios da região metropolitana).

Expressa-se nesta postura, a nosso ver, o reconhecimento de que a cidade numa sociedade em transição à era da informação não pode ser mais compreendida, exclusivamente, a partir da sua especificidade locacional - como fazem os que a vêem dentro de uma luta de todas contra todas -, mas em sua particularidade local dentro dos contextos de seus relacionamentos internos e externos, que perpassam todas as escalas desde o local até o global. ${ }^{2}$

Este reconhecimento, todavia, não exime e expurga o caráter destes planos estratégicos, que, por vezes, se colocam como uma panacéia para combater os handicaps competitivos e capacitar as municipalidades a auferir lucros. De fato estes planos, mais uma vez, tornaram-se fonte de lucro para consultorias, em uma reedição dos planos de desenvolvimento local e integrado da década de 60 e dos planos diretores pós anos 80 . A novidade reside hoje no fato de que isso ocorre nas mais diversas escalas - do local ao global e nas formas de construção da identidade e significado das cidades.

Enfim, a inicialmente apontada ambigüidade da urbanização generalizada, que pode tanto criar como destruir uma cidade, precisa ser mais aprofundadamente discutida a partir dos argumentos que arrolamos até aqui. Qual das duas alternativas prevalece (criar
2 Não cabe aqui aprofundar essas diferenciações entre "especificidades" e "particularidades"; para compreender toda sua profundidade, ver o tratado de Lefèbvre (1979) sobre a lógica dialética. 
Ester Limonad, arquiteta, é professora do Programa de Pós-Graduação em Geografia da Universidade Federal Fluminense. E-mail: limonad@superig.com.br

Rainer Randolph, economista, é professor do Instituto de Pesquisa e Planejamento Urbano e Regional da Universidade Federal do Rio de Janeiro. E-mail: randolph@uol.com.br ou destruir) depende, conforme Borja \& Castells (1997, p.363-72), da situação ou solução de cinco desafios. E, um destes desafios concerne ao que os autores chamam de significação (a cidade como produtora de sentido através de projetos urbanos que provocam adesão). Os demais, que não nos interessam no contexto da atual argumentação, seriam: competitividade e produtividade; segurança e seguridade (da convivência); sustentabilidade e governabilidade.

Se, no contexto da urbanização generalizada, uma cidade consegue cumprir essas exigências, ela se perpetuará ou mesmo fortalecerá; caso contrário, ela tende a se diluir. É esse papel integrador da representação que é explorado pelas formas estratégicas do planejamento como tentativa de conferir um novo protagonismo à cidade em relação ao desenvolvimento local.

Sem podermos aprofundar aqui essa análise, fica desde já patente que a forma nova de gerar uma identidade da cidade e uma identificação com a cidade lança mão de mecanismos de representação que deixam de ter seu referencial ético-cultural e assumem feições meramente instrumentais e ideológicas. Acreditamos que poderíamos, a partir desta percepção, aprofundar a crítica a um planejamento que não passa da (tentativa da) construção de um discurso hegemônico conservador.

De fato seria preciso juntar todas essas peças de quebra-cabeça (ou mosaico) para compreender a nova realidade: ainda como cidade ou como formas mais complexas de $l u$ gares? Seguindo Lefebvre (1972, p.21ss.), percebemos o quão distantes estamos ainda de uma solução:

Que hacer? Como construir ciudades o 'algo' que substitya a lo que antaño fue la ciudad? Como pensar el fenómeno urbano? ... Cuáles habrían de ser los progresos decisivos que habría que lograr para que la consciencia llegue a la altura de lo real (que la desborda) y de lo possible (que se le escapa)? El eje que describe el proceso se jalona así: ciudad política $\rightarrow$ ciudad comercial $\rightarrow$ ciudad industrial $\rightarrow$ zona crítica.

Estamos mergulhados, hoje, nessa zona crítica que pode, segundo o autor, ser o berço de uma nova sociedade caracterizada pelo urbano - onde, diríamos, as cidades não seriam mais de forma dominante os lugares dessa sociedade - isto é, a articulação entre espaço e sociedade.

\section{REFERÊNCIAS BIBLIOGRÁFICAS}

ARANTES, O. B. F. Cultura e transformação urbana. In: PALLAMIN, V. (Org.) Cidade e cultura. São Paulo: Estação Liberdade, 2002.

.Urbanismo em fim de linha: e outros estudos sobre o colapso da modernização arquitetônica. São Paulo: Edusp, 1998.

BENKO, G.; LIPIETZ, A. (Org.) As regiōes ganhadoras: distritos e redes - os novos paradigmas da geografia econômica. Oeiras: Celta, 1995.

BORJA, J.; CASTELLS, M. Local y global. Barcelona: Taurus, 1997.

CASTELLS, M. A sociedade em rede. Rio de Janeiro: Paz e Terra, 1999.

CHILDE, V. G. Man makes himself. New York: Mentor Books, 1951.

CORREAA, R. L.; ROSENDAHL, Z. (Org.) Matrizes da geografia cultural. Rio de Janeiro: Eduerj, 2001. 


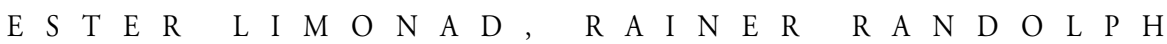

CORRÊA, R. L.; ROSENDAHL, Z. (Org.) Paisagem, imaginário e espaço. Rio de Janeiro: Eduerj, 2001.

DEL RIO, V. Introdução ao desenho urbano no processo de planejamento. São Paulo: Pini, 1990.

DEL RIO, V.; OLIVEIRA, L. (Org.) Percep̧̧ão ambiental. São Paulo: Nobel, 1999.

CULLEN, G. Paisagem urbana. Lisboa: Ediçōes 70, 1971.

FERRARA, L. D. Olhar periférico: informação, linguagem, percepção ambiental. São Paulo: Edusp, 1993.

GIDDENS, A. Time, space and regionalisation. In: GREGORY, D.; URRY, J. (Ed.) Social relations and spatial structures. London: Mac Millan, Cambridge, 1985.

GOODMAN, R. Despues de los urbanistas ¿Que? Madrid: Blume, 1977.

HARVEY, D. A condição pós-moderna. São Paulo: Loyola, 1989.

JACOBS, J. Cities and the wealth of nations. New York: Random House, 1984.

. The death and life of great American cities: the failure of urban planning. Middlesex: Pelican, 1974.

KEITH, M.; PILE, S. Introduction, part 2: The place of politics. In: KEITH, M.; PILE, S. (Ed.) Place and the politics of identity. London: Routledge, 1993.

KUUSISTO, A. K. Politics of place and resistance: the case of Northern Ireland. Nordia Geographical Publications Yearbook, v.28, n.2, 1999.

LEFÈBVRE, H. Espacio y politica. Barcelona: Peninsula, 1976.

. La revolución urbana. Madrid: Alianza, 1972.

. O direito à cidade. São Paulo: Documentos, 1969.

- O pensamento marxista e a cidade. Lisboa: Ulisseia, 1972a.

. The production of space. London: Blackwell, 1991.

LIMONAD, E. "Asi camina lo urbano: El derrotero". Revista Interamericana de Planificación, Guatemala, v.XXIV, n.95, jul-sep, 1991.

. Os lugares da urbanização. São Paulo, 1996. Tese (Doutoramento) - Faculdade de Arquitetura e Urbanismo, Universidade de São Paulo.

"Reflexōes sobre o espaço, o urbano e a urbanização". GEOgraphia, Niterói, n.1, ano I, p.71-92, 1999.

Espaço e tempo na arquitetura e urbanismo: algumas questôes de método. Anais do VII SEMINÁRIO DE HISTÓRIA DA CIDADE E DO URBANISMO. 2002. Salvador. Anais... Salvador: UFBA - Anpur, 2002 (CD-Rom).

MUMFORD, L. A cidade na história: suas origens, transformaçōes e perspectivas. São Paulo: Martins Fontes, 1998.

PAWLEY, M. Towards a digital urbanism. Revista Online Telepolis, Hannover: Verlag Heinz Heise, 1997a.

Why rebuild a phantom city? Revista Online Telepolis, Hannover: Verlag Heinz Heise, 1997b.

PRED, A. The social becomes spatial, the spatial becomes the social: enclosures, social change and the becoming of places in Skane. In: GREGORY, D.; URRY, J. (Ed.) Social relations and spatial structures. London: Mac Millan, 1985.

RANDOLPH, R. Urbanismo abstrato na era digital? Tentativa de uma provocação. V SEMINÁRIO SOBRE A HISTÓRIA DA CIDADE E DO URBANISMO. 1998. Campinas, SP. Anais... Campinas: PUC-Campinas. 1998 (CD-Rom).

"Sociedade-rede: paraíso ou pesadelo? Reflexões acerca de novas formas de articulação social e territorial das sociedades”. GEOgraphia, Niterói, ano I, n.2, p.27-54, 1999. 
. Las mutaciones de lo urbano: de la red de ciudades a la ciudad-red. In: FINQUELIEVICH, S. (Org.) ;Ciudadanos, a la red! Los vinculos sociales en el ciberespacio. Buenos Aires: Ciccus, 2000, p.21-38.

. "Em busca do urbano na cidade: 'andaduras porteñas' por lugares e lares da experiência sensorial, cognitiva e do espírito absoluto". Cadernos Ippur, v.16, n.1, 2002.

RANDOLPH, R.; LIMONAD, E. Digital cities, telecities, cidades em redes - caminhando para uma nova 'cooperação urbana'? In: Cuadernos de las II. Jornadas Internacionales "Ciudad y Informatica”. Quilmes: Universidade Nacional de Quilmes, 1998.

SANTOS, C. N. F. A Cidade como um jogo de cartas. Niterói: Eduff; São Paulo: Projeto, 1988.

SANTOS, M. Metamorfoses do espaço habitado. 2.ed. São Paulo: Hucitec, 1991. . A urbanização brasileira. São Paulo: Hucitec, 1993.

. Técnicas, espaço, tempo. São Paulo: Hucitec, 1994. . A natureza do espaço. São Paulo: Hucitec, 1996.

SAUER, C. O. Agricultural origins and dispersals. New York: American Geographical Society - Bowman Memorial Lectures, ser.2, 1952.

SOUZA, M. A. O novo Brasil urbano: integração ou fragmentação? In: GONÇALVES, M. F. (Org.) O novo Brasil urbano: impasses, dilemas, perspectivas. Anpur, 35a Reunião Anual da SBPC. Recife: Mercado Aberto, 1993. . Governo urbano. São Paulo: Nobel, 1988.

A B S T R A C T Our goal with this essay is to contribute to an up to date debate of the city and the urban representations in a way which tries to articulate concepts common to Architecture and Geography - departing from place concept. The argument will be presented in five parts: beginning with (i) the present relationship between city and urban brief characterisation where we have plenty signs pointing to an even more "trans-local" phenomena arisal; we will (ii) make a reflection about the local-place relationship, (iii) afterwards we deal with the significance and the representation - and their political-ideological importance on place formation - based on architecture and urbanism contributions, leading us to question (iv) place (cultural) identities generation to conclude (v) with the so-called strategic planning political-practical appropriation - dimension of the urban planning.

K E Y W O R D S City; place; representation; appropriation; urbanisation. 